\title{
MULTIPLE SOLUTIONS TO THE NONHOMOGENEOUS KIRCHHOFF TYPE PROBLEM INVOLVING A NONLOCAL OPERATOR
}

\author{
Wenjing Chen And Junhui XiE
}

Abstract. This paper examines the nonhomogenous Kirchhoff type equation that involves a nonlocal operator. Using Ekeland's variational principle and the Mountain pass theorem, the existence of multiple solutions is established.

Mathematics subject classification (2010): 35J20, 35J60, 47G20.

Keywords and phrases: Kirchhoff type problem, non-local integrodifferential operator, Ekeland's variational principle, Mountain pass theorem.

\section{REFERENCES}

[1] C.O. Alves, F.J.S.A. CorrêA, T.F. MA, Positive solutions for a quasilinear elliptic equation of Kirchhoff type, Comput. Math. Appl., 49, (1) (2005), 85-93.

[2] C. Chen, J. HuAng, L. LiU, Multiple solutions to the nonhomogeneous p-Kirchhoff elliptic equation with concave-convex nonlinearities, Applied Mathematics Letters, 26, (7) (2013), 754-759.

[3] C. CHEN, Y. KuO, T. WU, The Nehari manifold for a Kirchhoff type problem involving sign-changing weight functions, J. Differential Equations, 250, (4) (2011), 1876-1908.

[4] B. Cheng, X. Wu, Existence results of positive solutions of Kirchhoff type problems, Nonlinear Anal., 71, (10) (2009), 4883-4892.

[5] F.J.S.A. CorrêA, G. M. Figueiredo, On a p-Kirchhoff equation via Krasnoselskii's genus, Appl. Math. Lett., 22 (2009), 819-822.

[6] E. Di Nezza, G. Palatucci And E. Valdinoci, Hitchhiker's guide to the fractional Sobolev spaces, Bull. Sci. Math., 136 (2012), 521-573.

[7] I. EKeland, On the variational principle, J. Math. Anal. Appl., 47 (1974), 324-353.

[8] A. Fiscella, E. VAlDINOCI, A critical Kirchhoff type problem involving a nonlocal operator, Nonlinear Analysis, 94 (2014), 156-170.

[9] X. HE, W. Zou, Infinitely many positive solutions of Kirchhoff type problems, Nonlinear Anal. 70 (3)(2009), 1407-1414.

[10] D. LIU, P. ZHAO, Multiple nontrivial solutions to a p-Kirchhoff equation, Nonlinear Anal., 75 (2012), 5032-5038.

[11] K. Perera, Z. T. Zhang, Nontrivial solutions of Kirchhoff-type problems via the Yang index, J. Differential Equations, 221 (2006), no. 1, 246-255.

[12] P.H. RABINOWITZ, Minimax methods in critical point theory with applications to differential equations, CBMS Regional Conference Series in Mathematics, vol. 65, Published for the Conference Board of the Mathematical Sciences, Washington, DC, 1986.

[13] R. SeRVADEI AND E. VAldinoci, Lewy-Stampacchia type estimates for variational inequalities driven by (non)local operators, Rev. Mat. Iberoam., 29, (3) (2013), 1091-1126.

[14] R. Servadei And E. VAldinoci, Mountain Pass solutions for non-local elliptic operators, J. Math. Anal. Appl., 389 (2012), 887-898.

[15] R. SERVAdeI AND E. VAldinoci, Variational methods for non-local operators of elliptic type, Discrete and Continuous Dynamical Systems, 5 (2013), 2105-2137.

[16] J.J. SUN AND C.L. TANG, Existence and multiplicity of solutions for Kirchhoff type equations, Nonlinear Analysis, 74 (2011), 1212-1222. 
[17] Q. XIE, X. WU, C.L. TANG, Existence and multiplicity of solutions for Kirchhoff type problem with critical exponent, Commun. Pure Appl. Anal., 12, (6) (2013), 2773-2786.

[18] Z. Zhang, K. Perera, Sign changing solutions of Kirchhoff type problems via invariant sets of descent flow, J. Math. Anal. Appl., 317, (2) (2006), 456-463. 